\title{
What are the Benefits of Yoga for People with Diabetes?
}

\author{
Adriana D Ventura ${ }^{1,2 *}$ and Subhadra Evans ${ }^{1}$ \\ ${ }^{1}$ Deakin University, School of Psychology, Australia \\ ${ }^{2}$ The Australian Centre for Behavioural Research in Diabetes, Australia
}

Submission: March 08, 2018; Published: March 22, 2018

*Corresponding author: Adriana D Ventura, Deakin University, Geelong, School of Psychology, The Australian Centre for Behavioural Research in Diabetes, Diabetes Victoria, 570 Elizabeth Street, Melbourne, Australia, Tel: +61 039244 6351; Email: aventura@acbrd.org.au

Abstract

Research demonstrates that yoga has a positive, short-term impact on various diabetes-related biomedical outcomes. The majority of past research has examined adults with type 2 diabetes to the exclusion of adults with type 1 diabetes, despite their shared and unique selfmanagement challenges and risks of developing serious complications. Further, research investigating the impact of yoga on diabetes-related behavioural and psychological health factors are scarce. Due to the methodological limitations of existing studies, additional high-quality research is needed to explore the long-term impacts of yoga on a broad range of diabetes management outcomes, including behavioural and psychological health outcomes, for both adults with type 1 and type 2 diabetes.

Keywords: Diabetes; Self-management; Yoga; Psychological; Behavioural; Medical

\section{Introduction}

Diabetes refers to a group of metabolic conditions characterised by chronic high blood glucose [1]. There are two main types: type 1 diabetes (T1D), an auto-immune condition in which the pancreas does not produce insulin; and type 2 diabetes (T2D), a progressive condition in which the body becomes resistant to insulin and/or gradually loses capacity to produce insulin in sufficient quantity or potency. While T1D and T2D differ in their aetiology, they share the goal and challenge of maintaining optimal blood glucose levels in an effort to prevent/delay serious long-term complications, which can be life-threatening [2]. Haemoglobin A1c (HbA1c) represents the average blood glucose level over the past $10-12$ weeks, and is used as a clinical marker of blood glucose (glycaemic) control and complications risk [3].

Monitoring and managing blood glucose levels forms a core part of optimal diabetes self-management. This can include: frequent blood glucose checks, taking insulin and/or other blood glucose lowering medications, being physically active, and maintaining a healthy diet and weight. These daily activities can cause and be compounded by persistent cognitive, social and emotional burden. A common consequence of living with and managing diabetes is diabetes distress (i.e. negative emotional response to living with diabetes), which is associated with suboptimal HbA1c and impaired general emotional well-being [4]. Conversely, existing psychological problems (e.g. depression and anxiety) can impact negatively upon diabetes self-management, making this already burdensome task more complex [5]. Thus, managing psychological distress is an important aspect of diabetes self-management and living well with diabetes.

Due to the complexity of diabetes self-management, there has been increasing interest in the benefits of yoga for improving diabetes management and quality of life. However, little is known about the actual effects of this therapy for adults with T1D and T2D. Our aim is to examine the effects of yoga on diabetes self-management and medical, behavioural and psychological outcomes.

\section{Biomedical outcomes}

To date, the majority of studies examining the effects of yoga therapy on diabetes self-management have been focused on biomedical outcomes among adults with T2D or pre-diabetes. These findings have been summarised in three systematic reviews and one meta-analysis. It was found that yoga therapy is associated with multiple physical benefits, including significant reductions in fasting and postprandial blood glucose levels, HbA1c, total cholesterol and low-density lipoprotein, triglycerides, coronary stenosis, oxidative stress, blood pressure, body weight, waist-to-hip ratio, heart rate and catecholamine levels [6-9]. Some of these findings were confirmed by a more recent pre-post pilot study that examined the effects of a 10-day yoga-based lifestyle intervention on fasting blood glucose (FBG) levels [10]. This study used a large sample $(\mathrm{N}=1292$ of adults 
with T2D and pre-diabetes) and found a significant decrease in FBG post intervention $(\mathrm{p}<0.001)$. Although promising, there are methodological limitations of several of these past studies, including absence of control groups, small sample sizes, lack of clarity around the most beneficial forms of yoga and the 'dose' required for optimal outcomes; exclusion of adults with T1D; and limited insights into the long-term benefits of yoga on health outcomes.

\section{Behavioural and psychological outcomes}

A key limitation of the diabetes yoga literature has been the lack of focus on behavioural or psychological health outcomes, which is surprising given the importance of such outcomes to diabetes self-management. One recent 12 -week randomised controlled trial in India tested the effect of yoga as an intervention for adults with pre-diabetes and diagnosed diabetes [11]. Post intervention outcomes showed significant improvements in quality of life, as well as significant reductions in the Indian Diabetes Risk Score (IDRS). There was a significant difference $(\mathrm{p}<0.001)$ in both outcomes when study groups with standard treatment and yoga were compared with standard treatment alone, suggesting that yoga has greater health benefits to standard treatment alone. Another study examined the effects of yoga on clinical and psychological outcomes in 35 adults with T2D who attended a 40-day yoga camp [12]. Outcomes were measures pre-post intervention. A reduction in body mass index $(\mathrm{p}<0.001)$, anxiety $(\mathrm{p}<0.05)$ and an improvement in overall general well-being $(p<0.05)$ was found. Limitations of these studies include poor study design, absence of control group, small sample size and insufficient description of sampling. Furthermore, few studies have examined the long-term benefits of yoga, or factors that contribute toward uptake of yoga practice as a lifestyle intervention. A qualitative study explored perceptions of yoga among adults at risk of cardiovascular disease [13], some of whom had T2D diabetes ( $n=12)$. Four broad themes emerged from the content analysis, with participants reporting that practising yoga improved: overall physical functioning; stress/anxiety and enhanced calmness; quality of sleep; and efforts toward dietary improvement. This study offers insights into factors that may contribute toward yoga practice and maintenance over time, as well as key behavioral and psychological outcomes to examine in larger quantitative studies, including improved sleep, stress, and anxiety.

\section{Future directions}

Research in other health conditions has found that yoga reduces stress, symptoms of depression and anxiety, and improves sleep quality, coping, psychological well-being and quality of life $[14,15]$. Yoga may similarly offer adults with diabetes psychological benefits necessary for the management of a chronic and stressful condition (i.e. reduce diabetes distress, anxiety and improve quality of life). High-quality research is needed to examine these factors among adults with diabetes, including clear protocols for the yoga-interventions delivered. Further, inclusion of adults with T1D is essential. The psychological burden associated with diabetes is significantly greater for adults with T1D and adults with T2D using insulin therapy than those not using insulin, therefore exploring the benefits of yoga by diabetes type and treatment is a recommended approach for future research.

\section{Conclusion}

Yoga provides a potentially valuable opportunity for people with diabetes to engage in physical activity, an important behavioural component of diabetes management. In addition, yoga practices that work with the breath and the mind may help to provide relief from diabetes distress. Existing research suggests that yoga is a promising adjunct treatment for adults with T2D, potentially improving biomedical outcomes, including HbA1c. However, rigorous RCTs that include a range of biological and psychosocial outcomes are required before firm conclusions can be offered about the benefits and safety of yoga for people with T1D or T2D.

\section{Acknowledgement}

We thank Professor Jane Speight from the Australian Centre for Behavioural Research in Diabetes for her contribution to planning this review article.

\section{References}

1. World Health Organization (2016) Global report on diabetes.

2. McCarthy M, Whittemore R, Gholson G, Grey M (2017) Selfmanagement of physical activity in adults with type 1 diabetes. Appl Nurs Res 35: 18-23.

3. Cheung NW, Conn JJ, d'Emden MC, Gunton JE, Jenkins AJ, et al. (2009) Position statement of the Australian Diabetes Society: Individualisation of glycated haemoglobin targets for adults with diabetes mellitus. Med J Aust 19(6): 339-344.

4. Snoek FJ, Bremmer MA, Hermanns N (2015) Constructs of depression and distress in diabetes: Time for an appraisal. Lancet Diabetes \& Endocrinology 3(6): 450-460.

5. Snoek FJ, Skinner T (2002) Psychological counseling in problematic diabetes: Does it help? Diabet Med 19(4): 265-273.

6. Innes KE, Vincent HK (2007) The influence of yoga-based programs on risk profiles in adults with type 2 diabetes mellitus: A systematic review. Evid Based Complement Alternat Med 4(4): 469-486.

7. Innes KE, Selfe TK (2016) Yoga for adults with type 2 diabetes: A systematic review of controlled trials. J Diabetes Res 2016: 6979370.

8. Thind H, Lantini R, Balletto BL, Donahue ML, Salmoirago Blotcher E, et al (2017) The effects of yoga among adults with type 2 diabetes: A systematic review and meta-analysis. Prev Med 105: 116-126.

9. Cui J, Yan JH, Pan L, Le JJ, Yz G, et al. (2017) Effects of yoga in adults with type 2 diabetes mellitus: A meta-analysis. J Diabetes Investig 8(2): 201-209.

10. Rathi VV, Raghuram N (2017) Effect of short-term yoga-based lifestyle intervention on plasma glucose levels in individuals with diabetes and pre-diabetes in the community. Diabetes Metab Syndr 11 Suppl 2: S597-S599.

11. Keerthi GS, Pal GK, Sahoo JP, Sridhar MG, Balachander J, et al. (2017) Effects of 12 weeks of yoga therapy on quality of life and Indian 
Diabete Risk Score in normotensive Indian young adult prediateics and diabetics: Randomized controlled trial. J Clin Diagn Res 11(9): CC10CC14.

12. Kosuri M, Sridhar GR (2009) Yoga practice in diabetes improves physical and psychological outcomes. Metab Syndr Relat Disord 7(6) 515-517.

13. Alexander GK, Innes KE, Selfe TK,Brown CJ (2013) "More than expected": Perceived benefits of yoga practice among older adults at risk for cardiovascular disease. Complement Ther Med 21(1): 14-28.

his work is licensed under Creative Commons Attribution 4.0 License

DOI: 10.19080/JYP.2018.04.555639
14. Galliford M, Robinson S, Brudge P, Carmichael M (2017) Salute to the sun: a new dawn in yoga therapy for breast cancer. J Med Radiat Sci 64(3): 232-238.

15. Thayabaranathan T, Andrew NE, Immink MA, Hiller S, Stevens P, et al (2017) Determining the potential benefits of yoga in chronic stroke care: A systematic review and meta-analysis. Top Stroke Rehabil 24(4): 279-287.

Your next submission with Juniper Publishers
will reach you the below assets
- Quality Editorial service
- Swift Peer Review
- Reprints availability
- E-prints Service
- Manuscript Podcast for convenient understanding
- Global attainment for your research
- Manuscript accessibility in different formats
( Pdf, E-pub, Full Text, Audio)
- Unceasing customer service
Track the below URL for one-step submission
https://juniperpublishers.com/online-submission.php

